\title{
Evolution of asexual Daphnia pulex in Japan: variations and covariations of the digestive, morphological and life history traits
}

Xiaofei $\operatorname{Tian}^{*}$ (D), Hajime Ohtsuki and Jotaro Urabe

\begin{abstract}
Background: Several genetic lineages of obligate parthenogenetic Daphnia pulex, a common zooplankton species, have invaded Japan from North America. Among these, a lineage named JPN1 is thought to have started colonization as a single genotype several hundred to thousand years ago and subsequently produced many genotypes in Japan. To examine the phenotypic variations due to ecological drivers diverging the genotypes in new habitats, we measured heritability and variation in 17 traits, including life history, morphology and digestive traits, and the genetic distance among the D. pulex JPN1 genotypes in Japan.

Results: We found that most of the traits measured varied significantly among the genotypes and that heritability was highest in the morphological traits, followed by the digestive and life history traits. In addition, 93\% of the variation in these traits was explained by the first three components in the principal component analysis, implying that variation of these heritable traits is not random but rather converged into a few directions. These relations among traits revealed the potential importance of predation pressures and food conditions as factors for diverging and selecting different genotypes. However, the magnitude of the difference in any single trait group did not correlate with the genetic distance.

Conclusions: Our findings show that the divergent traits evolved within D. pulex JPN1 lineage without genetic recombination, since their ancestral clone invaded Japan. Large variations and covariations of the phenotypic traits, irrespective of the genetic distance among the genotypes, support the view that the invasive success of D. pulex JPN1 was promoted by a genetic architecture that allowed for large phenotypic variations with a limited number of functionally important mutations without recombination.
\end{abstract}

Keywords: Daphnia, Digestive traits, Genetic distance, Heritability, Invasive species, Life history traits, Morphological traits, Phenotypic distance

\section{Background}

Variations and relationships among heritable traits provide clues for identifying selective forces and thus understanding the evolution of species [1-3]. Specifically, if heritable traits diverged among isolated populations that shared common ancestral individuals, then we can analyse how phenotypic variation is related to genetic variation in terms of the ecological drivers promoting

\footnotetext{
* Correspondence: xiaofeitian0303@hotmail.com Graduate School of Life Sciences, Tohoku University, 6-3 Aramaki aza Aoba, Sendai 980-8578, Japan
}

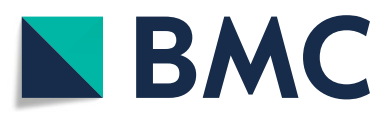

(c) The Author(s). 2019 Open Access This article is distributed under the terms of the Creative Commons Attribution 4.0 International License (http://creativecommons.org/licenses/by/4.0/), which permits unrestricted use, distribution, and reproduction in any medium, provided you give appropriate credit to the original author(s) and the source, provide a link to the Creative Commons license, and indicate if changes were made. The Creative Commons Public Domain Dedication waiver (http://creativecommons.org/publicdomain/zero/1.0/) applies to the data made available in this article, unless otherwise stated.

evolution. In general, populations of invasive species are founded by a few common ancestral individuals. Thus, examination of the phenotypic and genetic variations among these invasive populations is useful for unveiling the evolutionary processes that take place during the adaption to new habitats $[4,5]$.

Several genetic lineages of panarctic Daphnia pulex [6], a common zooplankton species, have invaded Japan from North America. Among these, a lineage named JPN1 is thought to have started the colonization as a single genotype several hundred to thousand years ago [7]. 
Although individuals of $D$. pulex JPN1 are obligate parthenogenetic animals, several genotypes (clones) were found within this lineage, suggesting that they genetically evolved without recombination after the initial invasion and likely adapted to new habitats in Japan [7]. Since they reproduce asexually, their populations are established by and composed of single genotypes $[8,9]$. If phenotypic traits vary among these genotypes (clones) and are heritable, then the genotypes of D. pulex that invaded Japan are a good model to explore whether the magnitude of the difference in the phenotypic traits is related to genetic distance among the genotypes and what environmental factors promoted evolution after Daphnia invasions into new habitats.

In nature, the abundance of Daphnia individuals is greatly influenced by a variety of environmental and biological factors, including interspecies interactions [1012]. Among these, predation is one of the important factors affecting Daphnia populations since it directly affects the survival rate [13-16] and indirectly affects reproduction when the survivors mature [17, 18]. In addition, Daphnia populations frequently suffer from deficiencies in the quantity and quality of algal food [19-21]. Therefore, several studies have examined intraspecific or genotype-specific differences in morphological and life history traits of Daphnia species under different predation pressures [22-24] and food conditions $[1,25-28]$. These studies showed that although the magnitude of variation caused by predators and food conditions differed among the phenotypic traits, the response of most traits was, to some extent, genotype specific. This suggests that at least some life history and morphological traits are heritable and that predation and food condition may have played crucial roles in selecting genotypes with different phenotypic traits, such as growth rate and maturation size.

To maximize their fitness under given food scarcity conditions with or without the presence of predators, animals must efficiently gain energy and nutrients from their food. Recent studies have suggested that in addition to a herbivore's feeding rate and digestive capacity, digestive enzyme activity is important for the animal's ability to cope with nutritionally suboptimal foods and maximize its fitness $[29,30]$. Thus, under different food conditions, genotypes with different digestive capacities are likely selected. Previous studies have shown that digestive enzyme activities are highly associated with the expression of related genes [31, 32]. However, few studies have examined whether digestive enzyme activity differs among genotypes and is thus a heritable trait.

In obligate parthenogenetic organisms, such as asexual individuals of $D$. pulex, the variation and relationship among phenotypic traits have noticeable implications for their evolution [33]. The substantial linkage of genes in asexual populations makes it impossible for a phenotypic trait to evolve independently of other traits [34, 35]. Accordingly, genotypes that are successfully maintained by given environmental conditions have likely both adaptive and non-adaptive traits [36,37]. If this is the case, then these traits are likely linked to each other across asexual genotypes. Conversely, if heritable differences in traits diverged evolutionally, without pleiotropic and epistatic effects [38], then it is likely that with an increasing number of base substitutions (mutations), the phenotypes will become more dissimilar among the genotypes. However, little is known about if and how life history, morphological and digestive traits are covaried in Daphnia [1] and how phenotypic differences in these traits are related to the genetic distance among genotypes.

To address these uncertainties, we examined the heritabilities of life history, morphology and digestive traits of $D$. pulex JPN1 genotypes. The heritability is a metrics measuring the degree of genetic attribute to a phenotypic resemblance between parental and offspring individuals in sexual organisms [2]. In the same sense, we used this term as the degree of genetic attribute to phenotypic similarity of a trait among asexual genotypes sharing the same ancestor individual. Our specific objectives were to clarify (1) if not only life history and morphology traits but also digestive traits are heritable, (2) how much these traits vary in response to changes in food conditions, (3) how much these traits covary with each other, and (4) if the magnitude of the phenotypic difference in heritable traits relates to individual genetic distance. By examining these variables, we explore the evolutionary ability of the phenotypic traits and ecological drivers that cause divergence in the phenotypes of a $D$. pulex lineage after invading Japan.

\section{Results}

Effects of genotype and food level on phenotypic traits

Both genotype (G) and food level (F) significantly affected 11 out of 17 traits (Table 1). Conversely, the growth coefficient $k$ and the body length at maturation and at day 5 only differed among genotypes, the intermoult duration before maturation differed between food levels, and the lipase activity and intermoult duration after maturation did not differ among genotypes or food levels (Table 1). Compared with these main effects, significant interaction effects of genotype and food level $(\mathrm{GxF})$ were found for a limited number of traits including beta-glucosidase and phosphatase activities for digestive traits and neonate size for morphological traits. Variances explained by genotype and food level differed highly among the traits. For example, $>60 \%$ of the variation in day 5 body length and relative tail-spine length were explained by the genotype, while the large 
Table 1 The effects of genotype, food level, and their interaction on phenotypic traits in Daphnia pulex

\begin{tabular}{|c|c|c|c|c|c|c|c|c|c|c|c|}
\hline \multirow[t]{2}{*}{ Trait } & \multirow[t]{2}{*}{ Mean } & \multirow[t]{2}{*}{ Range } & \multicolumn{3}{|c|}{ Genotype } & \multicolumn{3}{|l|}{ Food } & \multicolumn{3}{|c|}{ Genotype $\times$ Food } \\
\hline & & & F-value & $p$ & Var \% & F-value & $p$ & Var \% & F-value & $p$ & Var $\%$ \\
\hline \multicolumn{12}{|l|}{ Digestive } \\
\hline $\begin{array}{l}\text { Beta-glucosidase } \\
\text { (nmol hr. }^{-1} \text { mg }_{\text {protein }}^{-1} \text { ) }\end{array}$ & 322.8 & $93.9-680.6$ & 10.56 & $<0.001$ & 4.42 & 260.46 & $<0.001$ & 83.19 & 4.32 & 0.03 & 1.77 \\
\hline Lipase $\left(\mathrm{nmol} \mathrm{hr}{ }^{-1} \mathrm{mg}_{\text {protein }}{ }^{-1}\right.$ ) & 1949.4 & $1212.0-2789.4$ & 1.61 & 0.95 & 0.00 & 0.02 & 1.00 & 0.00 & 0.99 & 1.00 & 0.00 \\
\hline $\begin{array}{l}\text { Alkaline phosphatase } \\
\left(\mathrm{nmol} \mathrm{hr}^{-1} \mathrm{mg}_{\text {protein }}{ }^{-1}\right)\end{array}$ & 764.47 & $325.5-1526.2$ & 13.83 & $<0.001$ & 2.08 & 37.56 & $<0.001$ & 35.41 & 6.15 & 0.01 & 20.83 \\
\hline $\begin{array}{l}\text { Arginine amino-peptidase } \\
\left(\mathrm{nmol} \mathrm{hr}^{-1} \mathrm{mg}_{\text {protein }}^{-1}\right)\end{array}$ & 195.93 & $67.0-578.5$ & 6.46 & 0.01 & 8.80 & 125.17 & $<0.001$ & 80.00 & 0.38 & 1.00 & 0.00 \\
\hline $\begin{array}{l}\text { Alanine amino-peptidase } \\
\left(\text { nmol hr. }^{-1} \text { mgprotein }^{-1}\right)\end{array}$ & 178.05 & $82.9-310.1$ & 11.75 & $<0.001$ & 16.12 & 106.94 & $<0.001$ & 59.16 & 0.68 & 1.00 & 0.40 \\
\hline \multicolumn{12}{|l|}{ Life history } \\
\hline Maturation age (days) & 7.62 & $5.00-12.00$ & 9.48 & $<0.001$ & 12.55 & 96.81 & $<0.001$ & 65.21 & 0.20 & 1.00 & 0.00 \\
\hline Maturation instar number & 3.14 & $1.00-6.00$ & 4.66 & 0.02 & 10.40 & 36.65 & $<0.001$ & 45.60 & 0.96 & 1.00 & 0.09 \\
\hline Maturation body length (mm) & 1.61 & $1.32-1.90$ & 6.45 & $<0.001$ & 23.57 & 7.52 & 0.09 & 14.35 & 0.74 & 1.00 & 0.00 \\
\hline $\begin{array}{l}\text { Intermoult duration before } \\
\text { maturation (days) }\end{array}$ & 1.94 & $1.50-4.50$ & 1.62 & 1.00 & 4.21 & 9.56 & 0.03 & 20.20 & 0.05 & 1.00 & 0.00 \\
\hline $\begin{array}{l}\text { Intermoult duration after } \\
\text { maturation (days) }\end{array}$ & 2.31 & $2.00-2.67$ & 1.65 & 1.00 & 0.00 & 3.10 & 0.88 & 4.98 & 2.61 & 0.44 & 11.20 \\
\hline k & 0.11 & $0.06-0.17$ & 5.57 & 0.009 & 19.40 & 3.60 & 0.81 & 0.05 & 1.61 & 1.00 & 0.05 \\
\hline $\begin{array}{l}\text { Mean egg number of the first } \\
\text { three clutches }\end{array}$ & 6.19 & $1.67-12.50$ & 7.78 & $<0.001$ & 4.51 & 177.12 & $<0.001$ & 76.21 & 2.78 & 0.33 & 3.99 \\
\hline \multicolumn{12}{|l|}{ Morphology } \\
\hline $\begin{array}{l}\text { Mean neonate size of the first } \\
\text { three clutches }(\mathrm{mm})\end{array}$ & 0.63 & $0.50-0.78$ & 10.28 & $<0.001$ & 1.47 & 19.59 & $<0.001$ & 13.64 & 8.43 & $<0.001$ & 29.32 \\
\hline Body length at five days (mm) & 1.29 & $0.98-1.54$ & 21.26 & $<0.001$ & 64.66 & 2.16 & 0.30 & 1.37 & 1.18 & 0.67 & 1.64 \\
\hline Body weight at five days (mg) & 0.02 & $0.006-0.03$ & 15.52 & $<0.001$ & 47.37 & 11.84 & 0.001 & 15.79 & 1.72 & 0.34 & 5.26 \\
\hline $\begin{array}{l}\text { Relative tail spine length of the } \\
\text { first adult instar }\end{array}$ & 0.19 & $0.10-0.25$ & 41.78 & $<0.001$ & 75.67 & 18.87 & $<0.001$ & 0.00 & 2.49 & 0.66 & 5.88 \\
\hline$L_{\infty}(m m)$ & 2.45 & $1.89-3.10$ & 12.09 & $<0.001$ & 8.33 & 158.07 & $<0.001$ & 70.43 & 3.35 & 0.22 & 5.24 \\
\hline
\end{tabular}

The means and ranges of these traits examined for Daphnia JPN1 are shown with the variance components of each effect (Var \%). Statistically significant $p$-values $(<0.05)$ are shown in bold

variations in beta-glucosidase, arginine amino-peptidase, mean egg number, maturation age and maximum body length were explained by the present food level (Table 1). Thus, the effects of genotype and food level varied among the traits, even within the same trait category. However, on average, the proportion of the variance that was explained by the genotype was greater in morphological traits (mean 39.50\%) than in either digestive traits (mean $6.28 \%$ ) or life history traits (mean 10.66\%) (Table 1).

\section{Heritability and genetic variance}

Broad-sense heritability varied highly among the traits and ranged from 0 to 0.91 with a mean of 0.33 (Table 2). Among the three trait categories, heritability greater than 0.5 was often found in morphological traits but not in life history traits. Digestive traits showed relatively high heritability, except for lipase activity. The coefficients of genetic variation for the digestive traits were comparable to those of the morphological traits and were generally higher than those of the life history traits. In life history traits, maturation age showed the highest heritability, followed by maturation size and the growth coefficient (k). Since heritability was less than 0.1 for the intermoult durations of mature and immature individuals, and lipase activity showed no significant difference among the genotypes, we excluded these traits from the following analyses.

\section{Relationship among phenotypic traits}

Relationships among the traits were examined by principal component analysis (PCA) using best linear unbiased predictors (BLUPS). The first three components explained $93 \%$ of the variation in the traits examined. The eigenvectors of traits for each PCA showed that most of the life history traits contributed to the $\mathrm{PC} 1$, while most of the morphological traits contributed to the PC2. Digestive traits were not clustered together but distributed 
Table 2 Genetic variance, broad-sense heritability, 95\% confidence interval of heritability and coefficient of variation for 17 Daphnia phenotypic traits

\begin{tabular}{|c|c|c|c|c|}
\hline Trait & $\begin{array}{l}\text { Genetic variance } \\
\left(V_{g}\right)\end{array}$ & $\begin{array}{l}\text { Broad-sense heritability } \\
\left(\mathrm{H}^{2}\right)\end{array}$ & $\begin{array}{l}95 \% \text { confidence interval } \\
\text { of heritability }(\mathrm{Cl})\end{array}$ & $\begin{array}{l}\text { Coefficient of variation } \\
\text { (CV) }(\%)\end{array}$ \\
\hline \multicolumn{5}{|l|}{ Digestive } \\
\hline Beta-glucosidase & 1630.00 & 0.35 & $(0.00,0.31)$ & 12.51 \\
\hline Lipase & 8489.419 & 0.07 & $(0.00,0.17)$ & 38.42 \\
\hline Alkaline phosphatase & $13,060.00$ & 0.36 & $(0.00,0.63)$ & 14.95 \\
\hline Arginine amino-peptidase & 2128.45 & 0.41 & $(0.28,0.80)$ & 23.55 \\
\hline Alanine amino-peptidase & 845.20 & 0.56 & $(0.48,0.91)$ & 16.33 \\
\hline \multicolumn{5}{|l|}{ Life history } \\
\hline Maturation age & 0.48 & 0.41 & $(0.10,0.73)$ & 9.08 \\
\hline Maturation instar number & 0.13 & 0.20 & $(0.01,0.61)$ & 11.64 \\
\hline Maturation body length & 0.004 & 0.28 & $(0.00,0.08)$ & 3.92 \\
\hline Intermoult duration before maturation & 0.001 & 0.09 & $(0.00,0.48)$ & 1.95 \\
\hline Intermoult duration after maturation & 0.00 & 0.00 & $(0.00,0.19)$ & 0.00 \\
\hline k & 0.0002 & 0.12 & $(0.04,0.71)$ & 12.86 \\
\hline Mean egg number of the first three clutches & 0.28 & 0.23 & $(0.00,0.57)$ & 8.54 \\
\hline \multicolumn{5}{|l|}{ Morphology } \\
\hline Mean neonate size of the first three clutches & 0.00006 & 0.04 & $(0.00,0.08)$ & 1.22 \\
\hline Body length at five days & 0.02 & 0.67 & $(0.66,0.85)$ & 9.83 \\
\hline Body weight at five days & 0.00002 & 0.58 & $(0.66,0.87)$ & 27.61 \\
\hline $\begin{array}{l}\text { Relative tail spine length of the first adult } \\
\text { instar }\end{array}$ & 0.001 & 0.91 & $(0.44,0.72)$ & 17.99 \\
\hline$L_{\infty}$ & 0.01 & 0.31 & $(0.00,0.57)$ & 4.41 \\
\hline
\end{tabular}

into different PCs (Table 3): alkaline phosphatase and arginine amino-peptidase activities were strongly and moderately related to $\mathrm{PC} 1$, while alanine aminopeptidase and beta-glucosidase activities were negatively related to PC2 and PC3, respectively. The scores of these PCs were largely different among genotypes, indicating that a suite of these phenotypic traits differed among the genotypes (Fig. 1).

\section{Relationship between phenotypic similarity and individual genetic distance}

We estimated pairwise genetic distance among the genotypes according to their phylogenetic relationships (Additional file 1: Figure S1 and Additional file 2: Table S1). Then, we examined the relationships between the genetic distance and phenotypic differences in the overall traits, the trait groups (Additional file 3: Table S2) and single traits (Additional file 4: Table S3). No significant relationships were found between the genetic distance and any type of phenotypic trait examined (Fig. 2 and Additional file 5: Table S4).

\section{Discussion}

This study showed large variations in the expression of phenotypic traits among five asexual genotypes belonging to the JPN1 clade of $D$. pulex (as defined in So et al. [7]). Most of these phenotypic traits were significantly different among the genotypes and were heritable. So et al. suggested that these genotypes share the ancestral clone that originally invaded Japan [7]. In addition, So et al. [7] used a known mutation rate of mitochondrial deoxyribonucleic acid (mtDNA) [39] and number of base substitutions among JPN1 genotypes to estimate that an ancestral clone of the JPN1 clade arrived in Japan 680 2280 years ago [7]. Although this estimation has large uncertainty, it is not divergent from the phylogenetic relationship constructed from the data of 5282 single nucleotide polymorphisms (SNPs) in this study; therefore, these genotypes certainly share the same ancestral genotype. The possibility cannot be ruled out that different genotypes invaded Japan from a remote habitat by a single event or vector. However, if this were the case, then these genotypes were phenotypically similar to each other since they were produced from obligate parthenogenesis and likely invaded from a native habitat with a unique set of selection forces. Thus, considering the large variation in the heritable phenotypic traits, it is likely that the JPN1 genotypes ecologically diverged with various phenotypic traits since they invaded Japan. 
Table 3 Factor loading, eigenvalue and variance explained by the BLUPs of heritable phenotypic traits in the principal component analysis. Components with eigenvalues greater than 1.0 have been extracted to explain the variability of phenotypic traits

\begin{tabular}{llll}
\hline Phenotypic traits & \multicolumn{3}{l}{ Component } \\
\cline { 2 - 4 } & 1 & 2 & 3 \\
\hline$L_{\infty}$ & $\mathbf{0 . 9 9}$ & 0.05 & 0.10 \\
Maturation age & $\mathbf{0 . 9 3}$ & -0.36 & 0.05 \\
Maturation body length & $\mathbf{0 . 9 2}$ & 0.39 & 0.08 \\
Mean egg number of the first three clutches & $\mathbf{0 . 9 1}$ & 0.00 & -0.10 \\
Alkaline phosphatase & $\mathbf{0 . 8 9}$ & -0.45 & 0.07 \\
Maturation instar number & $\mathbf{0 . 8 7}$ & -0.33 & 0.34 \\
Arginine amino-peptidase & 0.62 & -0.53 & 0.19 \\
Body length at five days & 0.01 & $\mathbf{0 . 9 3}$ & 0.33 \\
Mean neonate size of the first three clutches & 0.25 & $\mathbf{0 . 9 3}$ & 0.19 \\
Body weight at five days & -0.20 & $\mathbf{0 . 9 1}$ & -0.10 \\
Relative tail spine length of the first adult instar & -0.07 & $\mathbf{0 . 9 1}$ & 0.41 \\
Alanine amino-peptidase & 0.36 & $\mathbf{- 0 . 8 4}$ & -0.14 \\
$k$ & -0.39 & $\mathbf{0 . 8 4}$ & -0.36 \\
Beta-glucosidase & -0.14 & -0.30 & $-\mathbf{0 . 9 1}$ \\
Eigenvalue & 7.33 & 4.62 & 1.12 \\
Variance contribution rate (\%) & 52.35 & 33.03 & 8.03 \\
Cumulative contribution rate (\%) & 52.35 & 85.38 & 93.41 \\
\hline
\end{tabular}

The loading scores greater than 0.80 and the highest compared to each of the other components are shown in bold

\section{Heritability of Daphnia traits}

According to Mousseau \& Rolf [40], who examined data from 75 species, the heritability of physiological traits is the same as that of morphological traits, which are both higher than that of life history traits. In general, it is expected that the responses of morphological and physiological traits to selection are faster than those of life history traits since the number of genes related to phenotypic variations are likely smaller in the former [41]. Since digestive enzyme activity is a physiological trait, it seems to be regulated by fewer genes compared with life history traits. Indeed, recent studies have shown that some digestive enzyme activities are highly related to the expression of a limited number of genes [31, 32]. Nonetheless, contrary to expectations, the heritability of the enzyme activities examined was lower than that of the morphological traits, although some of these showed slightly higher heritability than the life history traits. In this study, we estimated broad-sense heritability in asexual $D$. pulex genotypes since narrow-sense heritability is meaningless for asexual organisms [2]. Thus, caution is needed in understanding the implications of the heritability examined [42]. The low heritability determined in this study means that the variation is relatively lower among genotypes than among individuals within the genotypes. If all the genotypes have evolved under the same food environmental conditions, the digestive enzyme activities should have converged to the same levels among the genotypes. In addition, if food conditions vary temporally, it is disadvantageous for animals to evolve specific digestive traits. In nature, the abundance and species composition of algae that Daphnia prey on change not only seasonally but also spatially depending on trophic conditions [43]. Accordingly, although most of the enzyme activities were significantly different among genotypes, their heritability and thus their variation among the genotypes would be limited. Note that this differs somewhat from morphological and life history traits; digestive traits were related to different PCs
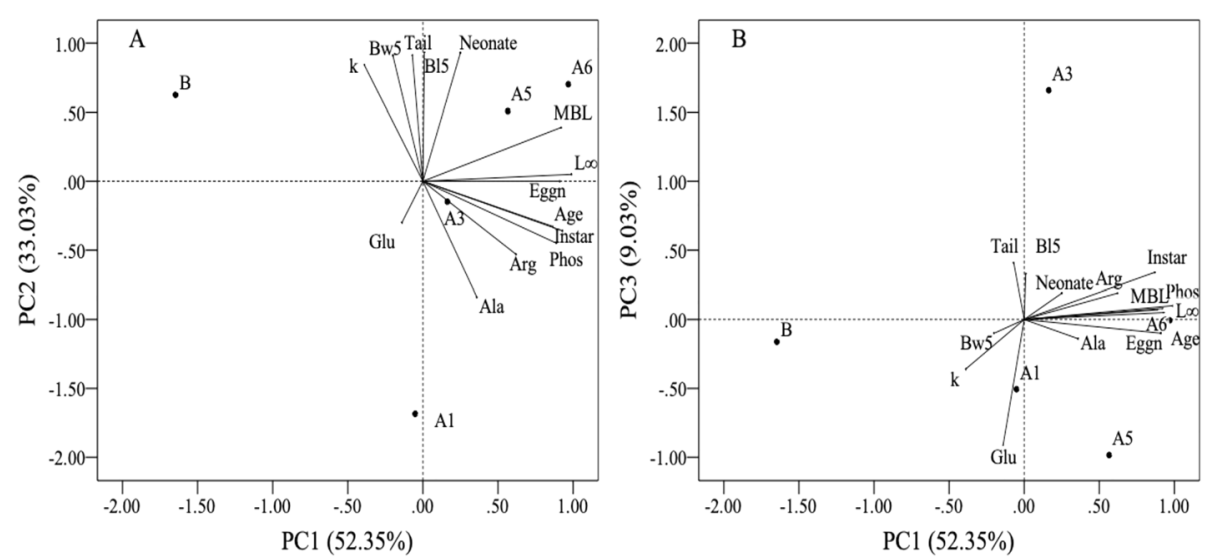

Fig. 1 Results of PCA showing a biplot of PC scores of JPN1 genotypes (A1, A3, A5, A6 and B) and loadings of phenotypic traits (Glu: betaglucosidase; Phos: alkaline phosphatase; Arg: arginine amino-peptidase; Ala: alanine amino-peptidase; Age: maturation age; Instar: maturation instar number; MBL: maturation body length; k: growth coefficient; Eggn: mean egg number of the first three clutches; Neonate: mean neonate size of the first three clutches; B15: body length at five days; Bw5: body weight at five days; Tail: relative tail-spine length of the first adult instar; $L_{\infty}$ : asymptotic body length). Panels $\mathbf{a}$ and $\mathbf{b}$ represent biplots of the $P C 1$ and $P C 2$, and the $P C 1$ and $P C 3$, respectively 


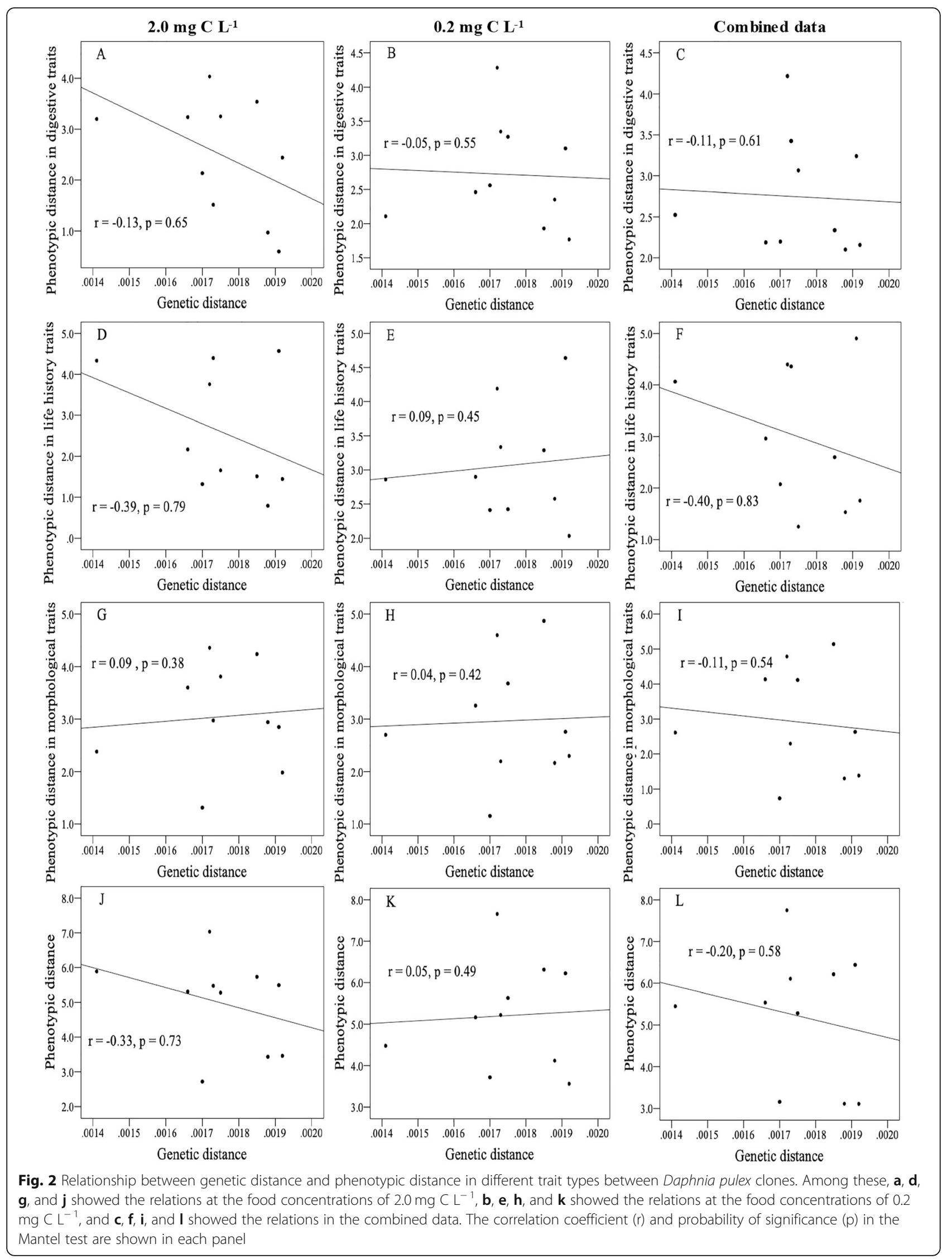


depending on the following enzymes: lipase, alkaline phosphatase and arginine amino-peptidase activities were related to $\mathrm{PC} 1$, while alanine amino-peptidase and beta-glucosidase were related to $\mathrm{PC} 2$ and $\mathrm{PC} 3$, respectively. These results suggest that JPN1 genotypes have evolved under variable food conditions that impeded genetic linkage among digestive traits.

\section{Genetic relations of traits and selective forces}

In this study, 93\% of the variation in phenotypic traits among the JPN1 clones was summarized by the first three PCs in the principal component analysis, suggesting that the direction of these variations is not random but converged into a few directions. The phenotypic traits, maturation age, instar and size, egg numbers for the first several clutches, and asymptotic size $\left(L_{\infty}\right)$ were positively correlated with each other. These results imply that clones that matured at an earlier age were of smaller size and produced a smaller number of eggs per clutch. These relationships suggest that maturation instar and size, egg number in the first several clutches and asymptotic size are determined solely by age when the Daphnia JPN1 clones mature. Thus, differences in these traits among clones may be a result of pleiotropic effects of mutation(s) that occurred in maturationrelated genes, such as hormone genes and other endocrine genes [44], rather than the additive effects of multiple genes related to maturation.

Among the heritable digestive enzyme activities, alkaline phosphatase was positively related to maturation and clutch sizes. A similar result was obtained for arginine amino-peptidase activity, but its relation with PC1 was not as strong. It should be noted that alkaline phosphatase was not limited to digestive enzymes [45]. However, since phosphorus is a key element for promoting body mass synthesis [46], genotypes with greater alkaline phosphatase activity may have been able to mature at larger sizes and produce larger numbers of eggs. This possibility implies that genes that regulate digestive enzyme activities are functionally linked with those regulating maturation.

Studies have shown that maturation size is a crucial factor in determining the colonization success of Daphnia in given habitats $[18,47,48]$. In aquatic ecosystems, most zooplanktivorous fish prey preferentially on large zooplankton individuals $[49,50]$. Therefore, in habitats inhabited by fish, individuals with early maturation have a higher probability of producing offspring $[14,50,51]$. In addition, it may be advantageous for Daphnia individuals not to grow continually and thus to have a small asymptotic size $\left(L_{\infty}\right)$ for maximizing their fitness in habitats with planktivorous fish. Heritable differences in maturation age and size suggest that habitat-specific variations in predation pressures may have acted as a selective force for the diverging JPN1 genotypes.

Apart from life history traits, most morphological traits such as body size (length and weight) at day 5, neonate size, tail-spine length and growth coefficient $(\mathrm{k})$ were positively related to the 2 nd PC. These results imply that genotypes with higher growth rates produce larger neonates with longer tail-spines. In small lakes and ponds where planktivorous fish were not yet abundant or were absent due to temporal drying or summer or winter kills [52], invertebrate predators such as midge larvae often dominated $[53,54]$. Since these invertebrate predators prey on small zooplankton, Daphnia individuals who rapidly attain larger sizes by postponing maturation have an advantage in reducing predation risk [17, $50,55]$. In addition, a longer tail-spine is known to be effective for Daphnia individuals to defend against predation by invertebrate predators $[10,56]$. Thus, being larger at birth and developing longer tail-spines seem to be a defensive strategy against invertebrate predation. As above, we argue that early maturation is a life history strategy for reducing size-specific mortality imposed by fish predation. However, these life history traits are not correlated with those of morphological traits in JPN1 genotypes. This fact suggests that traits for reducing predation risks from planktivorous fish and from invertebrate predators may have evolved separately among the $D$. pulex JPN1 genotypes.

Among the enzyme activities measured, the alanine amino-peptidase activity was negatively related to $\mathrm{PC}$, indicating that genotypes with higher growth rates had reduced activity of the enzyme. Thus, the difference in the activity of this enzyme among genotypes may be a result of a decrease in activity associated with increasing body size. Nonetheless, this covariation is somewhat puzzling since animals with higher growth rates should require more nitrogen $[57,58]$. One possibility is that in nature, $D$. pulex JPN1 genotypes may have experienced protein deficiencies in different manners. Although the cultured algae used in this study were sufficient in terms of nitrogen content relative to the demand of Daphnia [30], algal elemental and organic matter contents vary highly in natural lakes [20, 59, 60]. Thus, JPN1 genotypes with high digestive enzyme activity for amino acids may have been selected under food conditions that were deficient in protein. Alternatively, but not exclusively, in nature, Daphnia often experience deficiencies in biologically important chemicals such as phosphorus and essential fatty acids [20,30]. Under such conditions, it is disadvantageous for individuals to have high nitrogen digestion abilities since they have to then dispose of excess, assimilated chemicals to maintain their body stoichiometry [61-64]. This possibility implies that JPN 1 genotypes with low digestive enzyme activities for 
amino acids may have been selected under food conditions that were rich in proteins to increase their growth rates and tail-spine lengths to overcome invertebrate predation risks.

In this study, only beta-glucosidase activity was related to PC3. Since we could not rule out the possibility that this trait was directly or indirectly related to other traits that were not examined in this study, it was difficult to identify selective agents causing the genetic variation of this trait. However, the results showed that variation in this trait had evolved irrespective of the selective pressures posed by predators.

\section{Phenotypic divergence and genetic distance}

Although a number of studies have examined how phenotypic differentiation is related to genetic differentiation in populations $[1,65,66]$, few have examined how phenotypic dissimilarities are related to genomic differences among individuals. If variations of heritable phenotypes occurred mainly due to mutations in additive genes or polygenes, then it is expected that increasing heritable genomic differences will result in increasingly dissimilar heritable phenotypes. Relatedly, Burstin \& Charcosset [67] argued that relationships between genetic distances gauged by neutral genetic markers and phenotypic differentiation should follow a triangular pattern since large phenotypic variations are associated with large genetic variations, while small phenotypic variations are not always associated with small degrees of genetic variation. However, if large phenotypic variations emerge mainly as a result of pleiotropic effects of mutations in regulatory gene(s), then phenotypic differences would not relate to genomic distance. Supporting the latter case, neither the pairwise dissimilarities of any phenotypic categories nor the pairwise differences of any single phenotypic traits were significantly related to the pairwise genetic distances at the whole genome level (Fig. 2 and Additional file 5: Table S4). Plots of the phenotypic differences and dissimilarity against the genetic distance did not show the triangular pattern. Although our data are limited, the results suggest that large phenotypic variants of JPN1 clones have evolved mainly due to the pleiotropic effects of a limited number of mutations rather than a gradual accumulation of mutations in additive genes and polygenes.

\section{Conclusions}

This study showed that $D$. pulex JPN1 evolved divergent traits without genetic recombination for several hundred to thousand years since their ancestral clone originally invaded Japan. Variations in heritable traits suggest that predation pressures and food environments have played roles in the divergence and selection of these clones. Moreover, the relationship among these traits support the view that large phenotypic differences among JPN1 genotypes likely occurred mainly by pleiotropic effects of a limited number of mutated genes, rather than an "adaptive character complex" that was created by natural selection favouring certain combinations of genetically independent traits through independent mutations and recombination [68]. Similar to the present results, a lineage of Daphnia pulex and a green alga Caulerpa racemosa have successfully invaded and expanded their distributions in Africa [69] and in the Mediterranean [70], respectively, although they also do not reproduce sexually. The success of asexual organisms in new habitats is often attributable to their plasticity in phenotypic traits [71]. However, regardless of the magnitude of the plasticity, asexual individuals have limited adaptive capacity if their niche is frozen [72, 73]. Other than such phenotypic plasticity, Lee [4] suggested that genetic architecture within a genotype promoting high degrees of evolvability is a prerequisite for successful colonization by invasive species. This study supports such a view: a genetic architecture allowing for variations and covariations in heritable phenotypic traits present in D. pulex JPN1, which was established before invading Japan, may have produced various genotypes in the lineage that could adapt rapidly to a variety of novel lakes and ponds in Japan without genetic recombination by sexual reproduction. It is necessary to identify mutated genes among JPN1 clones to uncover the genetic architectures and linkages that promote such phenotypic divergence.

\section{Methods}

\section{Experimental materials}

Four distinct genetic groups (JPN1-4) of obligate parthenogenetic D. pulex are distributed in Japan [7]. Among these, JPN1 is estimated to have invaded Japan several hundred to thousand years ago and consists of several haplotypes [7]. In this study, we used five genotypes of the Daphnia pulex JPN1 lineage that were previously collected from ponds and small lakes in Japan and examined in So et al. [7]. Genotype A1 was collected from Lake Hataya Ohnuma (Yamagata Prefecture, latitude (N) $38.245^{\circ}$ longitude (E) $140.204^{\circ}$ ), A3 from Osawa Tame-ike Pond (Miyagi Prefecture, N 38.439 $\mathrm{E}$ $140.919^{\circ}$ ), A5 from Furuichi Oike Pond (Tottori Prefecture, N $35.391^{\circ} \mathrm{E} 133.339^{\circ}$ ), A6 from Arigatani-ike Pond (Shizuoka Prefecture, N 34.691 ${ }^{\circ}$ E $138.126^{\circ}$ ), and B from Daizahoshi-ike Pond (Nagano Prefecture, N $36.706^{\circ} \mathrm{E}$ $138.145^{\circ}$ ) [7].

Scenedesmus obliquus algae was cultured in a flowthrough system with COMBO [74], a defined freshwater culture medium for algae and zooplankton, and was used as the food source for Daphnia cultures. Before their use, algal cells were harvested, and their cell 
density was quantified under an optical microscope (Olympus, Tokyo, Japan). According to the previously measured carbon content for an algal cell of S. obliquus $\left(2.09 \times 10^{-8} \mathrm{mg} \mathrm{C} \mathrm{cell}^{-1}\right)$, the appropriate amounts of algae were estimated for achieving a designed carbon food level and then used in experiments.

Individuals in each genotype, taken from a single mother that originated from genotypes maintained for several years in our laboratory, were cultured in $900 \mathrm{ml}$ bottles containing $600 \mathrm{ml}$ of COMBO with $2.0 \mathrm{mg} \mathrm{C} \mathrm{L}^{-1}$ of S. obliquus in a controlled room $\left(20^{\circ} \mathrm{C}\right.$, photoperiod, $\operatorname{Light}(\mathrm{L})$ : $\operatorname{Dark}(\mathrm{D})$ 14:10). The individuals were transferred to fresh medium every other day and fed daily. The individual abundance in the culture bottles was adjusted to less than 1 individual $20 \mathrm{ml}^{-1}$ in all the clones. Then, neonates born within $24 \mathrm{~h}(\mathrm{hr})$ were collected from the 3rd brood produced by the cultured individuals and used for the following experiments.

\section{Assay of digestive enzyme activity}

In each clone, 20 neonates were randomly chosen and individually placed into $50-\mathrm{ml}$ stoppered bottles containing the growth medium COMBO with $S$. obliquus. Half of the Daphnia were grown at a food concentration of $2.0 \mathrm{mg} \mathrm{C} \mathrm{L}^{-1}$, and the other half were grown at $0.2 \mathrm{mg} \mathrm{C}$ $\mathrm{L}^{-1}$. The animals were fed daily and moved to new medium every two days. After a 4-day cultivation, on day 5, 10 individuals of each treatment were randomly collected. At least 5 individuals were used for the measurements of body length and body weight, and the remaining individuals were used for measuring digestive enzyme activity.

For measurements of body length and weight, 5-dayold animals were rinsed twice in distilled water and placed under a microscope where media was removed until the animals were properly positioned. Using an Olympus DP20 camera (Olympus, Tokyo, Japan) mounted on an Olympus SZH10 stereomicroscope (Olympus, Tokyo, Japan), images of Daphnia were captured at a magnification of $40 \times$, and their body length from the base of the tail-spine to the top of the head was subsequently measured using ImageJ software (National Institutes of Health, Bethesda, USA). Then, they were individually transferred into a pre-weighed aluminium boat, dried for $24 \mathrm{~h}$ at $60^{\circ} \mathrm{C}$, cooled for $12 \mathrm{~h}$ in a vacuum desiccator at room temperature, and weighed using a Mettler-Toledo UMX2 microbalance to the nearest $0.1 \mu \mathrm{g}$ (Mettler-Toledo, Tokyo, Japan).

For assaying the digestive enzyme activities, the animals were rinsed several times with distilled water, homogenized with a micropestle in $200 \mu \mathrm{l}$ of ice-cold Tris/ $\mathrm{HCl}$ buffer $\left(0.05 \mathrm{~mol} \mathrm{~L}^{-1}, \mathrm{pH} 8\right)$, and centrifuged for 10 $\min (\mathrm{min})$ at $14,000 \times$ gravitational acceleration $(\mathrm{g})$ using a KUBOTA 1120 centrifuge (Kubota, Tokyo, Japan). The supernatant of the centrifuged samples was treated as an extract of a single animal for the analysis of betaglucosidase (EC no. 3.2.1.21), lipase (3.1.1.3 and others), alkaline phosphatase (3.1.3.1), arginine amino-peptidase (3.4.11.6) and alanine amino-peptidase (3.2.11.2). Assays were run at room temperature with $5 \mu$ l of substrate, $15 \mu \mathrm{l}$ of sample extract and $230 \mu \mathrm{l}$ of citrate-phosphate buffer (0.1 $\left.\mathrm{mol} \mathrm{L}^{-1}, \mathrm{pH} 5\right)$ [75] for beta-glucosidase or Tris/HCl buffer for alkaline phosphatase $\left(0.05 \mathrm{~mol} \mathrm{~L}^{-1}\right.$, $\mathrm{pH} 8)$ and other enzymes $\left(0.05 \mathrm{~mol} \mathrm{~L}^{-1}, \mathrm{pH} 7\right)$, according to the protocol developed by Knotz et al. [76]. The substrates used in the enzyme assays were 4methylumbelliferyl beta-d-glucoside (Sigma M3633) for beta-glucosidase, 4-methylumbelliferyl butyrate for lipase (Sigma 19,362), L-arginine-7-amido-4-methylcoumarin hydrochloride (Sigma A2027) for arginine aminopeptidase, and L-alanine-4-methyl-7-coumarinylamidetrifluoroacetate (Sigma A4302) for alanine aminopeptidase. Stock solutions of these substrates were prepared in ethylene glycol monomethyl ether $\left(5 \mathrm{mmol} \mathrm{L}^{-1}\right)$ . The concentration of these substrates in the assays was $100 \mu \mathrm{mol} \mathrm{L}^{-1}$. Fluorescence was measured at $360 \mathrm{~nm}$ (excitation) and $450 \mathrm{~nm}$ (emission) every $5 \mathrm{~min}$ for 35 min with a Fluoroskan Ascent microplate fluorometer (Thermo Fisher Scientific, Tokyo, Japan). Blanks were run in parallel. For preparing standard curves, $0 \sim 10 \mu \mathrm{mol} \mathrm{L}^{-1}$ of 4-beta-methylubelliferone (MUF) and 7-amino-4-methylcoumarin (AMC) were used [76].

The water-soluble protein content of the animals was measured using a bicinchoninic acid assay (BCA) [77]. Bovine serum albumin (BSA: 0, $50 \mathrm{mg} \mathrm{L}^{-1}, 100 \mathrm{mg} \mathrm{L}^{-1}$ ) was used as the standard. For these measurements, $100 \mu \mathrm{L}$ of supernatant from the centrifuged sample or BSA was mixed with $750 \mu \mathrm{L}$ of the working reagent of the bicinchoninic acid kit (BCA1 SIGMAALDRICH) and incubated for $2 \mathrm{~h}$ at $55^{\circ} \mathrm{C}$. The assays were read at $562 \mathrm{~nm}$ using a UV-1600 spectrophotometer (Shimadzu, Tokyo, Japan). Digestive enzyme activity was calculated corresponding to the average water-soluble protein content of each clone in a specific unit (nmol hr. $\left.{ }^{-1} \mathrm{mg}_{\text {protein }}{ }^{-1}\right)$.

\section{Growth experiment}

A growth experiment was performed at the two food concentrations mentioned above. For each food concentration, 10 neonates of each clone were individually grown in $50-\mathrm{ml}$ stoppered bottles containing the growth medium COMBO with algal food as in the experiment for measuring digestive enzyme activities. In this study, the experiment lasted until they had produced the sixth brood. To ensure that the food particles were homogeneous in the suspension, the bottles were secured to a grazing wheel that rotated at a speed of 1 revolution per 
minute (rpm). The growth medium and algal food were changed every two days, and Daphnia were fed daily.

When the growth medium was changed, images of the animals were captured as above and used for measuring the body length from the base of the tail-spine to the top of the head, the tail-spine length and the number of eggs in the brood pouch. In this study, maturation was defined as the time when the eggs first appeared in the brood pouch. The frequency of moulting casts (exuviae) and the size of newly released neonates were also counted and removed from the bottle.

The von Bertalanffy growth curve was applied for estimating the asymptotic body length $L_{\infty}$ and growth coefficient $k$ as follows:

$$
L_{t}=L_{\infty} \times\left\{1-\exp \left[-k\left(t-t_{0}\right)\right]\right\}
$$

where $L_{t}$ is the body length at age $t$ (days), $t_{0}$ is the hypothetical age at ' 0 ' body length.

\section{Genetic analysis}

To estimate the phylogenetic relationships and the genetic distances among Daphnia clones, we used genetic data acquired from our whole-genome sequencing as described below. Fifty to seventy individuals of each clone were used for DNA extraction conducted using a Maxwell $^{(\mathrm{R})} 16$ instrument and Maxwell ${ }^{(\mathrm{R})} 16$ LEV Plant DNA Kit (Promega). Construction of the library and sample sequencing were performed at the Beijing Genomics Institute (BGI) JAPAN (Kobe, Japan). The libraries were constructed by a unique method of BGI JAPAN (low input method) from more than $500 \mathrm{ng}$ of DNA per sample. The libraries were sequenced on an Illumina Hiseq $\mathrm{X}^{\mathrm{ix}}$ Ten platform (Illumina, San Diego, CA, USA) using a paired-end $150 \mathrm{bp}$ (PE150) strategy to obtain approximately $8 \mathrm{~Gb}$ data/sample (approximately 40x coverage). The data were filtered using MapReduce accelerationsupported (SOAPunke) software [78] with the following options: -n 0.1, - 10, -q 0.5, -i and -A 0.5. Reads of the individual FASTQ files were mapped to the reference genome data of $D$. pulex isolate PA42 [79] using burrows-wheeler alignment (BWA) [80]. Removal of potential polymerase chain reaction (PCR) duplicates and detection of polymorphisms in the data were conducted using sequence alignment/map(SAM) tools [81]. The proportion of different sites (uncorrected p-distance) was calculated using sequence data $(135,933,993$ basepairs (bps)) with a $>20$ quality score as the pairwise genetic distances among clones. To clarify the phylogenetic relationship among clones, we constructed an unrooted phylogenetic tree by the maximum likelihood (ML) method using SNP data with SNPhylo [82]. In this tree, we included several genotypes used in So et al. [7] other than JPN1 clones: D. pulex JPN2 (HO01) was collected from Lake Hataya Ohnuma (Yamagata Prefecture, N $38.245^{\circ} \mathrm{E} 140.204^{\circ}$ ), JPN3 (AWA) from Lake Awaji nariai-ji (Hyogo Prefecture, N 34.283 E $134.809^{\circ}$ ) and JPN4 (SUM) from Sumiyoshi ike Pond (Kagoshima Prefecture, $\mathrm{N} 31.772^{\circ} \mathrm{E} 130.592^{\circ}$ ), a genotype of $D$. pulex (LL05) was collected from a small lake in Manitoba, Canada (longitude/latitude unknown), and D. pulicaria (PUC01) was collected from Lake Biwa (Shiga Prefecture, $\mathrm{N} 35.176^{\circ} \mathrm{E} 136.979^{\circ}$ ).

\section{Statistical analysis}

In this study, we measured a total of 17 phenotypic traits for each of the 5 clones (genotypes) that were grouped and categorized as enzyme activity (five traits), life history traits (seven traits) and morphological traits (five traits) (Table 1). A two-way analysis of variance (ANOVA) was used to examine the effects of genotype, food level, and their interaction (GxF) on each of the phenotypic traits. Significant effects were determined at $p<0.05$, and $\alpha$ level was adjusted by a Bonferroni correction when multiple tests were performed. In these analyses, genotype and GxF were set as random factors, food level was set as a fixed factor, and variance components were estimated using the restricted maximum likelihood (REML) parameter. Before the analysis, a logtransformation was performed for beta-glucosidase, alkaline phosphatase, arginine amino-peptidase, maturation age, mean egg number of the first three clutches and body length at five days, and a two-step transformation algorithm [83] was performed for intermoult duration before maturation to stabilize the variance.

Broad-sense heritability $\left(\mathrm{H}^{2}\right)$ for each trait was calculated as follows:

$$
\mathrm{H}^{2}=\mathrm{V}_{\mathrm{g}} / \mathrm{V}_{\mathrm{T}},
$$

where $\mathrm{V}_{\mathrm{g}}$ is the genetic variance and $\mathrm{V}_{\mathrm{T}}$ is the total phenotypic variance [2]. The $95 \%$ confidence interval (CI) of heritability for each trait was estimated using the bootstrap method. The $\mathrm{V}_{\mathrm{g}}$ was estimated by decomposing $\mathrm{V}_{\mathrm{T}}$ using two-way ANOVA according to Holland et al. [84]. Then, the coefficient of genetic variation $(\mathrm{CV})$ was calculated as follows:

$$
\mathrm{CV}=\mathrm{V}_{\mathrm{g}} 0.5 / \mu,
$$

where $\mu$ is the mean value of given phenotypic traits.

To detect the relationships among traits, we first estimated the best linear unbiased predictors (BLUPs) of genotype values (sample number $=5$ clones, Additional file 6: Table S5) for each trait based on the analysis above. Then, PCA was estimated using the BLUPs of heritable traits. Components with eigenvalues greater than 1.0 have been extracted to explain the variability of phenotypic traits. We used the BLUPs since these 
are more robust to unbalanced replication and less biased by environmental effects than the genotype mean values [85].

We examined the relationship between phenotypic dissimilarity and genetic distance among five genotypes. For this, we estimated the standardized Euclidean distance using the BLUPs of each trait. The distance was estimated for overall traits, traits in each category and single traits. Individual genetic distance was estimated using uncorrected $\mathrm{p}$-distances by pairwise comparisons of the genome sequences between genotypes. Then, we examined the relationship between two matrices of genomic and phenotypic traits by a Mantel test.

These statistical tests were conducted with Statistical Product and Service Solutions (SPSS) statistics version 21.0 (International business machines corporation (IBM), Armonk, USA) and R version 3.3.3 [86].

\section{Additional files}

Additional file 1: Figure S1. Phylogenetic relationships of five clones in JPN1 lineage and other clones. This is based on 5282 SNPs from whole genome sequence data. Using data with quality scores higher than 20 , a phylogenetic tree of the clones by the maximum likelihood (ML) method were constructed using SNPhylo pipeline [82]. Numbers on branches indicate bootstrap values (> 50\% are shown). In this analysis, we included genotypes used in So et al. [7] other than D. pulex JPN1 clones. These are D. pulex JPN2 (HO01), JPN3 (AWA) and JPN4 (SUM) and a genotype of D. pulex (LL05) collected from a small lake in Manitoba, Canada, and D. pulicaria (PUC01) collected from Lake Biwa. (PDF 199 kb)

Additional file 2: Table S1. Genetic distance measured by proportion of different sites ( $p$-distance) among Daphnia pulex JPN1 clones ( $A 1, A 3$, A5, A6 and B). (PDF $46 \mathrm{~kb}$ )

Additional file 3: Table S2. Distance of phenotypes in each category among Daphnia pulex JPN1 clones (A1, A3, A5, A6). The phenotypic distance was calculated using difference in BLUPs between clones. (PDF $51 \mathrm{~kb}$ )

Additional file 4: Table S3. Distance of single phenotypes among Daphnia pulex JPN1 clones (A1, A3, A5, A6 and B). The phenotypic distance was calculated using difference in BLUPs between clones. (PDF 68 kb)

Additional file 5: Table S4. Relationship between genetic distance and phenotypic distance between clones in each of the single traits. (PDF $55 \mathrm{~kb}$ )

Additional file 6: Table S5. BLUPS of each trait in Daphnia pulex JPN1 clones. (PDF $69 \mathrm{~kb}$ )

\section{Abbreviations}

AMC: 7-amino-4-methylcoumarin; ANOVA: Analysis of variance; BCA: Bicinchoninic acid assay; BGl: The Beijing Genomics Institute; BLUPs: Best linear unbiased predictors; bps: Branch-point sequence; BSA: Bovine serum albumin; BWA: Burrows-wheeler alignment; $\mathrm{Cl}$ : Confidence interval; $\mathrm{COMBO}$ : A defined freshwater culture medium for algae and zooplankton; CV: Coefficient of genetic variation; D. pulex: Daphnia pulex; E: Longitude; F: Food level; G: Genotype; g: Gravitational acceleration; GxF: Genotype by food level interaction; $\mathrm{H}^{2}$ : Broad-sense heritability; hr.: Hour; IBM: International business machines corporation; k: Growth coefficient; L: D: Light: Dark; $L_{\infty}$ : Asymptotic body length; $L_{t}$ : Body length at age t; min: Minute; ML: Maximum likelihood; mtDNA: Mitochondrial deoxyribonucleic acid; MUF: 4-beta-methylubelliferone; N: Latitude; PCA: Principal component analysis; PCR: Polymerase chain reaction; REML: Restricted maximum likelihood; rpm: Revolutions per minute; $S$. obliquus: Scenedesmus obliquus; SAMtools: Sequence alignment/ map(SAM)tools; SNP: Single nucleotide polymorphism; SNPhylo: A pipeline to construct a phylogenetic tree from huge SNP data; SOAPunke: A MapReduce acceleration-supported software for integrated quality control and preprocessing of high-throughput sequencing data; SPSS: Statistical product and service solutions; SSR: Simple sequence repeat; t: Age (days); $t_{0}$ : Hypothetical age at ' 0 ' body length; $V_{\mathrm{g}}$ : Genetic variation; $\mathrm{V}_{\mathrm{T}}$ : Total phenotypic variance; $\mu$ : Mean value of phenotypic traits

\section{Acknowledgements}

We thank three anonymous reviewers for helpful and constructive comments.

\section{Authors' contributions}

$\mathrm{XT}$ and $\mathrm{JU}$ designed the study and performed the growth and enzyme activity assay experiments. HO performed the genetic analysis. XT and JU wrote the draft of the manuscript and all authors contributed to the revision. All named authors have read and approved the final manuscript.

\section{Funding}

This study was financially supported by a MEXT Scholarship by Japanese Government to XT and Grants-in-Aid for Scientific Research (KAKENHI $16 \mathrm{H} 02522)$ to $\mathrm{JU}$. The funding bodies had no role in the design of the study, in the collection, the analysis or the interpretation of data and in writing the manuscript.

\section{Availability of data and materials}

Traits data used in this study are available on Dryad (doi: https://doi.org/10. 5061/dryad.9p2j626). Daphnia genetic data are available from the authors upon request.

Ethics approval and consent to participate

Not applicable.

\section{Consent for publication}

Not applicable.

\section{Competing interests}

The authors declare that they have no competing interests.

Received: 6 October 2018 Accepted: 6 June 2019

Published online: 13 June 2019

\section{References}

1. Spitze K. Population structure in Daphnia obtusa: quantitative genetic and allozymic variation. Genetics. 1993;135:367-74.

2. Lynch W, Walsh B. Correlations between characters. In: Lynch M, editor. Genetics and analysis of quantitative traits. Sunderland: Sinauer Associates; 1998. p. 629-47.

3. Josephs EB, Stinchcombe JR, Wright SI. What an genome-wide association studies tell us about the evolutionary forces maintaining genetic variations for quantitative traits. New Phytol. 2017;214:21-33.

4. Lee CE. Evolutionary genetics of invasive species. Trends Ecol Evol. 2002;17: 386-91. https://doi.org/10.1016/S0169-5347(02)02554-5.

5. Davidson AM, Jennions M, Nicotra AB. Do invasive species show higher phenotypic plasticity than native species and, if so, is it adaptive? A metaanalysis. Ecol Lett. 2011;14:419-31.

6. Colbourne JK, Crease TJ, Weider LJ, Hebert PDN, Dufresne F, Hobaek A. Phylogenetics and evolution of a circumarctic species complex (Cladocera: Daphnia pulex). Bio J Linn Soc. 1998;65:347-65 1006/bijl.1998.0251.

7. So M, Ohtsuki $H$, Makino W, Ishida S, Kumagai $H$, Yamaki KG, et al. Invasion and molecular evolution of Daphnia pulex in Japan. Limnol Oceanogr. 2015; 60:1129-38.

8. Crease TJ, Stanton DJ, Hebert PDN. Polyphyletic origins of asexuality in Daphnia pulex. II: mitochondrial-DNA variation. Evolution. 1989;43:1016-26.

9. Hebert PDN, Beaton MJ, Schwartz SS, Stanton DJ. Polyphyletic origins of asexuality in Daphnia pulex. I: breeding-system variation and levels of clonal diversity. Evolution. 1989:43:1004-15.

10. McCauley E, Murdoch WW. Predator-prey dynamics in environments rich and poor in nutrients. Nature. 1990;343:455-7.

11. Weetman D, Atkinson D. Antipredator reaction norms for life history traits in Daphnia pulex: dependence on temperature and food. Oikos. 2002;98:299-307. 
12. Andras JP, Ebert D. A novel approach to parasite population genetics: experimental infection reveals geographic differentiation, recombination and host-mediated population structure in Pasteuria ramosa, a bacterial parasite of Daphnia. Mol Ecol. 2013;22:972-86.

13. Brooks $J \mathrm{~L}$, Dodson SI. Predation, body size, and composition of plankton. Science. 1965;150:228-35.

14. Zaret TM. Life history and growth relationships of Cichla ocellaris, a predatory south American cichlid. Biotropica. 1980;12:144-57.

15. Vanni MJ. Effects of food availability and fish predation on a zooplankton community. Ecol Monogr. 1987;57(1):61-88.

16. Chang KH, Hanazato T. Vulnerability of cladoceran species to predation by the copepod Mesocyclops leuckarti: laboratory observations on the behavioural interactions between predator and prey. Freshw Biol. 2003; 48(3):476-84.

17. Lynch M. Fitness and optimal body size in zooplankton population. Ecology. 1977;58(4):763-74

18. Gliwicz ZM, Boavida MJ. Clutch size and body size at first reproduction in Daphnia pulicaria at different levels of food and predation. J Plankton Res. 1996;18(6):863-80.

19. Lampert $\mathbf{W}$. The relative importance of food limitation and predation in the seasonal cycle of two Daphnia species. SIL Proceedings, 1922-2010. 1988; 23(2):713-8

20. Elser JJ, Hayakawa K, Urabe J. Nutrient limitation resouces food quality for zooplankton: Daphnia response to seston phosphorus enrichment. Ecology. 2001;82(3):898-903.

21. DeMott MR, Gulati RD, Donk EV. Daphnia food limitation in three hypereutrophic Dutch lakes: evidence for exclusion of large-bodied species by interfering filaments of cyanobacteria. Limnol Oceanogr. 2001;46(8): 2054-60.

22. Stoks R, Govaert L, Pauwels K, Jansen B, De Meester L. Resurrecting complexity: the interplay of plasticity and rapid evolution in the multiple trait response to strong changes in predation pressure in the water flea Daphnia magna. Ecol Lett. 2016;19(2):180-90.

23. Spitze K. Predator-mediated plasticity of prey life history and morphology: Chaoborus americanus predation on Daphnia pulex. Am Nat. 1992;139(2): 229-47.

24. Boersma M, Spaak P, De Meester L. Predator-mediated plasticity in morphology, life history, and behavior of Daphnia: the uncoupling of responses. Am Nat. 1998;152(2):237-48.

25. Lynch M. Spontaneous mutations for life history characters in an obligate parthenogen. Evolution. 1985;39:804-18.

26. De Meester L. An estimation of the heritability of phototaxis in Daphnia magna Straus. Oecologia. 1989;78:142-4.

27. Tessier AJ, Consolatti NL. Resource quantity and offspring quality in Daphnia. Ecology. 1991;72:468-78. https://doi.org/10.2307/2937188.

28. Prater C, Wagner ND, Frost PC. Interactive effects of genotype and food quality on consumer growth rate and elemental content. Ecology. 2017;98: 1399-408.

29. Boersma M, Schöps C, McCauley E. Nutritional quality of seston for the freshwater herbivore Daphnia galeata $\times$ hyalina: biochemical versus mineral limitations. Oecologia. 2001;129:342-8.

30. Urabe J, Shimizu Y, Yamaguchi T. Understanding the stoichiometric limitation of herbivore growth: the importance of feeding and assimilation flexibilities. Ecol Lett. 2018;21:197-206.

31. Koussoroplis AM, Schwarzenberger A, Wacker A. Diet quality determines lipase gene expression and lipase/esterase activity in Daphnia pulex. Biol Open. 2017;6:210-6. https://doi.org/10.1242/bio.022046.

32. Schwarzenberger A, Fink P. Gene expression and activity of digestive enzymes of Daphnia pulex in response to food quality differences. Comp Biochem Physiol Part - B Biochem Mol Biol. 2018;218:23-9. https://doi.org/ 10.1016/j.cbpb.2018.01.009

33. Holsinger KE, Ellstrand NC. The evolution and ecology of permanent translocation heterozygotes. Am Nat. 1984;124:48-71.

34. Hill WG, Robertson $A$. The effect of linkage on limits to artificial selection. Genet Res. 1966;8:269-94.

35. Lande R. The genetic correlation between characters maintained by selection, linkage and inbreeding. Genet Res. 1984;44:309. https://doi.org/10. 1017/S0016672300026549.

36. Barton NH, Turelli M. Evolutionary quantitative genetics: how little do we know? Annu Rev Genet. 1989;23:337-70. https://doi.org/10.1146/annurev.ge. 23.120189.002005.
37. Spitze K, Burnson J, Lynch M. The covariance structure of life-history characters in Daphnia pulex. Evolution. 1991;45:1081-90. https://doi.org/10. 2307/2409717

38. Stern DL, Orgogozo V. The loci of evolution: how predictable is genetic evolution? Evolution. 2008;62:2155-77.

39. Xu S, Schaack S, Seyfert A, Choi E, Lynch M, Cristescu ME. High mutation rates in the mitochondrial genomes of Daphnia pulex. Mol Biol Evol. 2012; 29:763-9. https://doi.org/10.1093/molbev/msr243.

40. Mousseau TA, Roff DA. Natural selection and the heritability of fitness components. Heredity. 1987;59:181-97. https://doi.org/10.1038/hdy.1987.113.

41. Merilä J, Sheldon BC. Testis size variation in the greenfinch Carduelis Chloris: relevance for some recent models of sexual selection. Behav Ecol Sociobiol. 1999:45:115-23.

42. Ebert D. The trade-off between offspring size and number in Daphnia magna: the influence of genetic, environmental and maternal effects. Arch Hydrobiol Suppl. 1993;90:453-73.

43. Huszar VLM, Caraco N. The relationship between phytoplankton composition and physical-chemical variables: a comparison of taxonomic and morphological-functional descriptors in six temperate lakes. Freshw Biol. 1998;40(4):679-96.

44. Flatt T, Tu MP, Tatar M. Hormonal pleiotropy and the juvenile hormone regulation of Drosophila development and life history. BioEssays. 2005;27: 999-1010. https://doi.org/10.1002/bies.20290.

45. Wojewodzic MW, Kyle M, Elser JJ, Hessen DO, Andersen T. Joint effect of phosphorus limitation and temperature on alkaline phosphatase activity and somatic growth in Daphnia magna. Oecologia. 2011;165(4):837-46.

46. Sterner RW, Elser JJ. Ecological stoichiometry: the biology of elements from molecules to the biosphere. Princeton: Princeton University Press; 2002.

47. Culver D, Kerfoot WC. Seasonal variation in the sizes at birth and at first reproduction in Cladocera. Chapter 34. In: Evolution and ecology of zooplankton communities. 1980.

48. Leibold M, Tessier AJ. Constrasting patterns of body size for Daphnia species that segregate by habitat. Oecologia. 1991;86:342-8.

49. Werner EE, Hall DJ. Optimal foraging and the size selection of prey by the bluegill sunfish (Lepomis Macrochirus). Ecology. 1974;55:1042-52. https://doi. org/10.2307/1940354.

50. Zaret TM, Kerfoot WC. Fish predation on Bosmina longirostris: body-size selection versus visibility selection. Ecology. 1975;56:232-7. https://doi.org/ 10.2307/1935317.

51. Beckerman A, Petchey OL, Morin PJ. Adaptive foragers and community ecology: linking individuals to communities and ecosystems. Funct Ecol. 2010;24:1-6.

52. Brönmark C, Pettersson L, Nilsson A. Predator-induced defense in crucian carp. In: Tollria R, Harvell CD, editors. The ecology and evolution of inducible defenses. Princeton: Princeton University Press; 1999. p. 203-17.

53. Dodson SI. Adaptive change in plankton morphology in response to sizeselective predation: a new hypothesis of cyclomorphosis. Limnol Oceanogr. 1974;19:721-9

54. Gliwicz ZM. Relative significance of direct and indirect effects of predation by planktivorous fish on zooplankton. Hydrobiologia. 1994;272:201-10

55. Hall DJ, Threlkeld ST, Burns CW, Crowley PH. The size-efficiency hypothesis and the size structure of zooplankton communities. Annu Rev Ecol Syst. 1976;7:177-208

56. Laforsch C, Tollrian R. Inducible defenses in multipredator environments: cyclomorphosis in Daphnia cucullata. Ecology. 2004:85:2302-11.

57. Anderson TR, Pond DW. Stoichiometric theory extended to micronutrients: comparison of the roles of essential fatty acids, carbon, and nitrogen in the nutrition of marine copepods. Limnol Oceanogr. 2000;45(5):1162-7.

58. Raubenheimer D, Simpson SJ, Mayntz D. Nutrition, ecology and nutritional ecology: toward an integrated framework. Funct Ecol. 2009;23(1):4-16.

59. Ahlgren G, Goedkoop W, Markensten H, Sonesten L, Boberg M. Seasonal variations in food quality for pelagic and benthic invertebrates in Lake Erken - the role of fatty acids. Freshw Biol. 1997;38:555-70.

60. Elser JJ, Fagan WF, Denno RF, Dobberfuhl DR, Folarin A, Huberty A, et al Nutritional constraints in terrestrial and freshwater food webs. Nature. 2000; 408:578-80.

61. Urabe J, Sterner RW. Contrasting effects of different types of resource depletion on life-history traits in Daphnia. Funct Ecol. 2001;15:165-74. https://doi.org/10.1046/j.1365-2435.2001.00511.x.

62. Darchambeau F, Faerøvig PJ, Hessen DO. How Daphnia copes with excess carbon in its food. Oecologia. 2003;136:336-46. 
63. Anderson TR, Hessen DO, Elser JJ, Urabe J. Metabolic stoichiometry and the fate of excess carbon and nutrients in consumers. Am Nat. 2005;165:1-15. https://doi.org/10.2307/3473193.

64. Suzuki-Ohno Y, Kawata M, Urabe J. Optimal feeding under stoichiometric constraints: a model of compensatory feeding with functional response. Oikos. 2012;121:569-78.

65. Reed DH, Frankham R. How closely correlated are molecular and quantitative measures of genetic variation? A meta-analysis. Evolution. 2001;55:1095-103.

66. Leinonen T, O'Hara RB, Cano JM, Merilä J. Comparative studies of quantitative trait and neutral marker divergence: a meta-analysis. J Evol Biol. 2008:21:1-17.

67. Burstin J, Charcosset A. Relationship between phenotypic and marker distances: theoretical and experimental investigations. Heredity. 1997;79: 477-83.

68. Endler JA. Multiple-trait coevolution and environmental gradients in guppies. Trends Ecol Evol. 1995;10:22-9.

69. Mergeay J, Verschuren D, De Meester L. Invasion of an ansexual American water flea clone thoughout Africa and rapid displacement of a native sibling species. Proc R Soc B. 2006;273:2839-44.

70. Durand C, Manuel M, Boudouresque CF, Meinesz A, Verlaque M, Le Parco Y. Molecular data suggest a hybrid origin for the invasive Caulerpa racemosa (Caulerpales, Chlorophyta) in the Mediterranean Sea. J Evol Biol. 2002;15(1): 122-33.

71. Richards CL, Bossdorf O, Muth NZ, Gurevitch J, Pigliucci M. Jack of all trades, master or some? On the role of phenotypic plasticity in plant invasions. Ecol Lett. 2006;9(8):981-93.

72. Pound GE, Cox SJ, Doncaster CP. The accumulation of deleterious mutations within the frozen niche variation hypothesis. J Evol Biol. 2004;17(3):651-62.

73. Vrijenhoek RC. Factors affecting clonal diversity and coexistence. Integr Comp Biol. 1979;19(3):787-97.

74. Kilham SS, Kreeger DA, Lynn SG, Goulden CE, Herrera L. COMBO: a defined freshwater culture medium for algae and zooplankton. Hydrobiologia. 1998; 377:147-59.

75. Mcllvaine TC. A buffer solution for colorimetric comparison. J Biol Chem. 1921;49:183-6

76. Knotz S, Boersma M, Saborowski R. Microassays for a set of enzymes in individual small marine copepods. Comp Biochem Physiol - A Mol Integr Physiol. 2006;145:406-11.

77. Smith PK, Krohn Rl, Hermanson GT, Mallia AK, Gartner FH, Provenzano MD, et al. Measurement of protein using bicinchoninic acid. Anal Biochem. 1985; 150:76-85.

78. Chen Y, Chen Y, Shi C, Huang Z, Zhang Y, Li S, et al. SOAPnuke: a MapReduce acceleration-supported software for integrated quality control and preprocessing of high-throughput sequencing data. Gigascience. 2018; 7:1-6.

79. Ye Z, Xu S, Spitze K, Asselman J, Jiang X, Ackerman MS, et al. A new reference genome assembly for the microcrustacean Daphnia pulex. G3 (Bethesda). 2017;7:1405-16.

80. Li H, Durbin R. Fast and accurate short read alignment with burrowswheeler transform. Bioinformatics. 2009;25:1754-60.

81. Li H, Handsaker B, Wysoker A, Fennell T, Ruan J, Homer N, et al. The sequence alignment/map format and SAMtools. Bioinformatics. 2009;25: 2078-9.

82. Lee TH, Guo H, Wang X, Kim C, Paterson AH. SNPhylo: a pipeline to construct a phylogenetic tree from huge SNP data. BMC Genomics. 2014;15:1-6.

83. Templeton GF. A two-step approach for transforming continuous variables to normal: implications and recommendations for IS research. Commun Assoc Inf Syst. 2011;28:41-58.

84. Holland JB, Nyquist WE, Cervantes-Martínez CT. Estimating and interpreting heritability for plant breeding: an update. In: Janick J, editor. Plant breeding reviews. New York: John Wiley \& Sons; 2003. p. 70-3.

85. Shaw RG, Platenkamp GA, Shaw FH, Podolsky RH. Quantitative genetics of response to competitors in Nemophtla menziesii: a field experiment. Genetics. 1995;406:397-406.

86. R Core Team. R: a language and environment for statistical computing. Vienna, Austria: R Foundation for Statistical Computing; 2016.

\section{Publisher's Note}

Springer Nature remains neutral with regard to jurisdictional claims in published maps and institutional affiliations.

\section{Ready to submit your research? Choose BMC and benefit from}

- fast, convenient online submission

- thorough peer review by experienced researchers in your field

- rapid publication on acceptance

- support for research data, including large and complex data types

- gold Open Access which fosters wider collaboration and increased citations

- maximum visibility for your research: over $100 \mathrm{M}$ website views per year

At BMC, research is always in progress.

Learn more biomedcentral.com/submissions 